\title{
Evaluation of urban freight transport operations in Surakarta city
}

\author{
Yulianto Budi ${ }^{1, *}$ \\ ${ }^{1}$ Civil Engineering Department, Engineering Faculty, Sebelas Maret University, Jl. Ir. Sutami 36A, \\ Surakarta (57126), Indonesia
}

\begin{abstract}
In an effort to monitor and control the urban freight transport, the Municipal Government of Surakarta City issue a dispensation license for freight vehicles through the inner-city road. Nevertheless, the facts indicate that traffic violations by freight vehicles against the provisions of existing regulations are relatively high and thus have the potential to decrease the level of safety, road service and environmental sustainability. This is due to the weakness of the system of monitoring and the control of urban freight transport is low both in terms of technicality and legality. The research's aims are to evaluate and improve the current system of monitoring and control of urban freight transport related to the provision of the dispensation license for freight vehicles through the inner-city road in Surakarta City. The analysis results indicate that the percentage of unlicensed urban freight transport is significant in number, and no clarity is associated with licensing dispensation for urban freight transport weighing $>9,000 \mathrm{~kg}$, a significant number of traffic violations, road bearing capacity of freight transport routes do not correspond to the vehicle weight. Various recommendations are proposed for improving the current system of monitoring and of the control of urban freight transport.
\end{abstract}

\section{Background}

The growth of urban economy is highly dependent on the reliable supply of goods and commodity logistics. At the same time, the presence of uncontrolled urban freight transport has the potential to cause infrastructure damage, traffic congestion, traffic accidents, air pollution and noise. Therefore, a firm transportation policy from the Central and City Government is required to optimize the urban freight transport operation so that its negative impacts can be overcome.

Transportation policies relating to urban freight transport operations have been established in law or regulation [1-5]. Conditions to be met by urban freight transport, including freight routes based on road class and road bearing capacity, allowed vehicle weight, operating time, loading procedures, parking facilities, loading-unloading and warehousing. In connection with this, it is necessary to have a system of monitoring and of controlling urban freight transport. In an effort to monitor and control the urban freight transport, the Municipal Government of Surakarta City issue a dispensation license for freight

*Corresponding author: budi.yulianto@ft.uns.ac.id 
vehicles through the inner-city road in Surakarta City. Such licensing is granted to freight vehicles that have some certain criteria, such as vehicle carrying goods whose dimensions of size and weight cannot be separated into smaller parts, vehicles whose heavy loads exceed the heaviest axle load limit allowed for the road class, and vehicles containing basic necessities and / or fuel [4].

Nevertheless, the facts on the ground show that traffic violations by freight vehicles against the provisions of existing regulations in the Surakarta City are relatively high and results in a potential to decrease the level of safety, road service and environmental sustainability [1]. This is due to the weakness of the current system to monitor and control freight transport both in terms of technicality and legality. Figure 1 shows some violations of freight vehicles related to a) route does not match the road class b) loading procedure c) parking on shoulder of the road d) loading-unloading of goods.
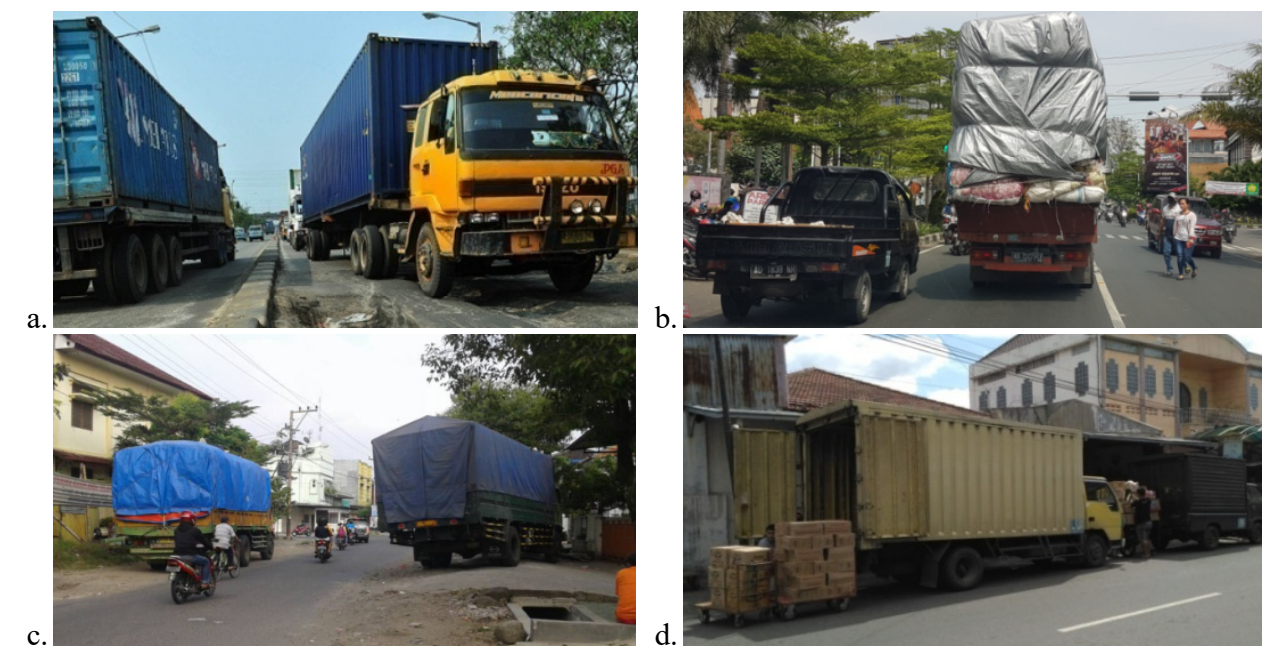

Fig. 1. Violations of freight vehicle associated to a) route does not match the road class b) loading procedure c) parking on shoulder of the road d) loading-unloading of goods.

Based on the facts, therefore, it is necessary to improve the current system of monitoring and controlling urban freight transport related to the provision of the dispensation license for freight vehicles through the inner-city road in Surakarta City, which contains the determination of route, vehicle weight, operating time and law enforcement.

\section{Research methods}

This research discusses the evaluation and improvement of the current system of monitoring and controlling urban freight transport in Surakarta City. The research stages include identifying problems and objectives of the research; data collection; identifying the characteristics of urban freight transport movement, the road bearing capacity of road networks, the performance of road networks and violation of urban freight transport regulations; determining urban freight transport routes through the inner-city road in Surakarta City for vehicles with a certain weight; updating the urban freight transport dispensation license administration system in Surakarta City; and making a conclusion. 


\section{Data collection, analysis and results}

\subsection{Characteristics of urban freight transport movement}

Characteristics of urban freight transport movement analysis is carried out to find out the number of urban freight transport under the dispensation license, the number of urban freight transport based on vehicle weight classification, the type of goods transported by urban freight transport and distribution patterns of urban freight transport movement.

\subsubsection{Data collection}

For the purpose of analysing characteristics of urban freight transport movement, data is taken at the Levies Collection Place (LCP) and the Department of Transportation (DoT) office, where the dispensation license is granted. Ten LCPs location are located on the main road in and out of Surakarta City, see Figure 2.

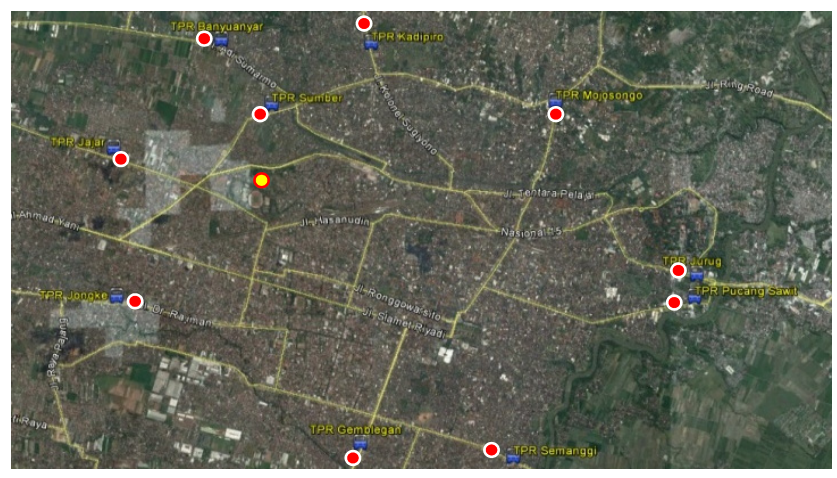

Fig. 2. Map of LCPs and DoT office location in Surakarta City.

Data collection is done in two conditions, namely condition 1, where all LCPs and DoT office function for data collection of the dispensation license. Data was collected in November 2016. Condition 2, where only LCP Kadipiro, LCP Semanggi and DoT office function for data collection of the dispensation license. In this case, other TPRs are closed due to the policy of Surakarta City Mayor related to illegal levies issue. Data was collected in January and February 2017. Data collected include vehicle type and weight, type of goods, origin and destination of urban freight transport movement.

\subsubsection{Analysis and results}

Survey data was analyzed and recapitulated in vehicle weight classification, type of goods, origin and destination of urban freight transport movement. The number of urban freight transport under the dispensation license in November 2016, January 2017 and February 2017 are 3,241 vehicles, 916 vehicles and 741vehicles, consecutively. Analysis results show that there is a decreasing trend of the number of urban freight transport licensed by the dispensation from November 2016 to February 2017. The decrease in the number of urban freight transport licensed by the dispensation between November 2016 and January 2017 is $71.7 \%$, between January 2017 and February 2017 is 19.1\%, while between November 2016 and February 2017 is $77.1 \%$.

The top ten destinations of urban freight transport in Surakarta City can be seen in Figure 3. In general, land use that attracts the largest urban freight transport travels are markets such as Legi Market, Gede Market, Klewer Market and shopping areas such as Gading, Tipes, 
Gemblegan, Nonongan. In general, the type of goods which are dominantly transported are food, packages, materials, and convection.

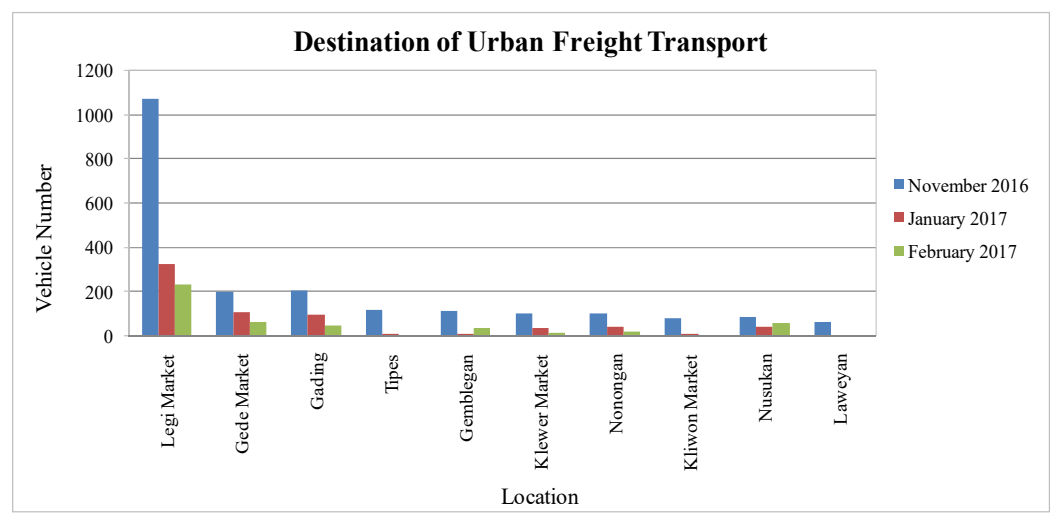

Fig. 3. Top ten destination of urban freight transport in Surakarta City.

The classification of vehicle weight licensed by dispensation is divided into three classes, namely $>4,500-6,000 \mathrm{~kg},>6,000-7,500 \mathrm{~kg}$ and $>7,500-9,000 \mathrm{~kg}$. The data analysis shows that vehicle weight $>6,000-7,500 \mathrm{~kg}$ is the most, followed by $>4,500-6,000 \mathrm{~kg}$ and $>7,500-$ $9,000 \mathrm{~kg}$, see Figure 4. This trend is consistent for all periods in November 2016, January 2017 and February 2017.

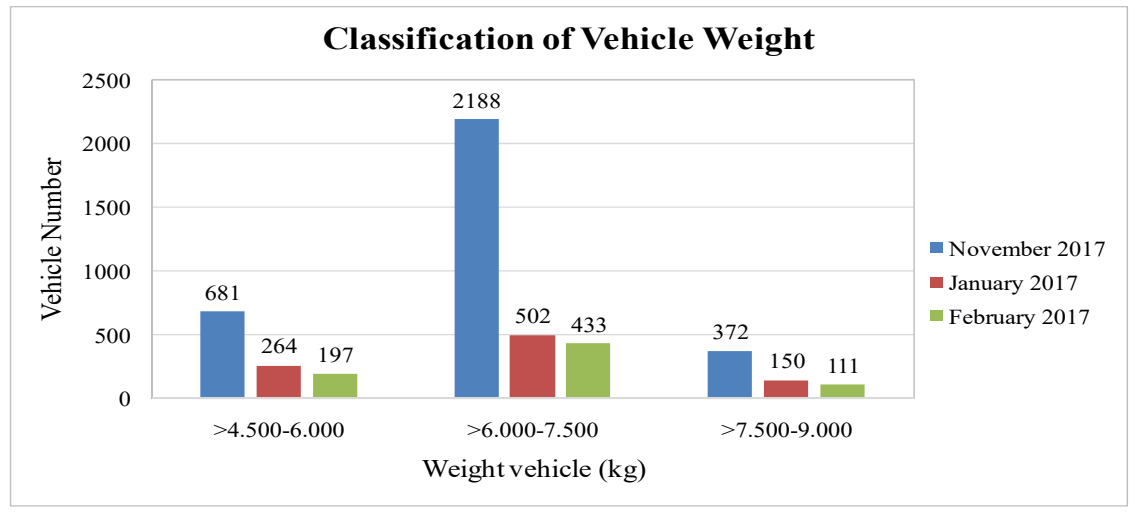

Fig. 4. Classification of vehicle weight of urban freight transport in Surakarta City.

Distribution patterns of urban freight transport movement can be obtained from the origin and destination data of each freight vehicle entering Surakarta City. Figure 5 shows the desired lines of urban freight transport movement in Surakarta City. 


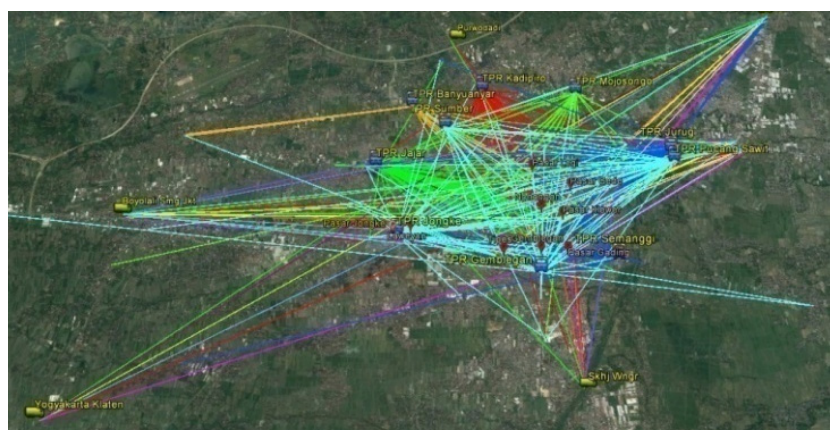

Fig. 5. Distribution patterns of urban freight transport movement in Surakarta City.

\subsection{Road bearing capacity}

The mapping of road bearing capacity in Surakarta City is carried out to know the potential of the road usage for urban freight transport routes according to the vehicle weight. Determination of road bearing capacity based on pavement technical data of the Department of Public Works and traffic sign data of the Department of Transport Surakarta City. The road bearing capacity is divided into several classes based on vehicle weight. Figure 6 shows the map of road bearing capacity in Surakarta City.

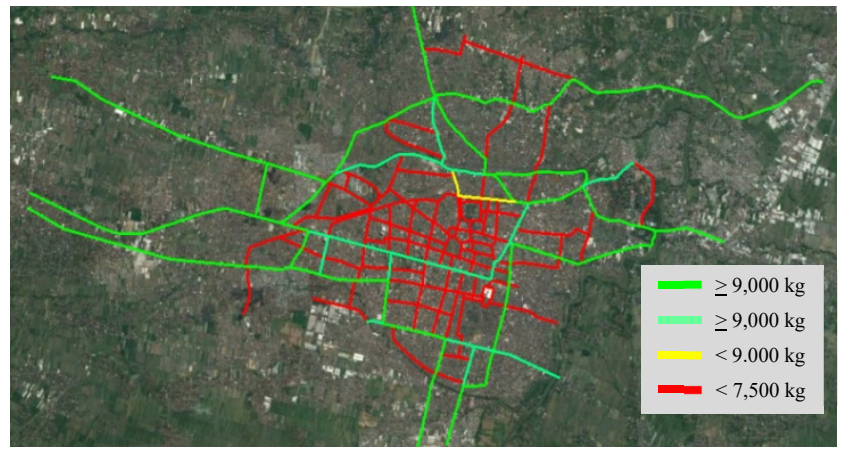

Fig. 6. Map of road bearing capacity in Surakarta City.

\subsection{Road traffic performance}

The presence of urban freight transport in traffic has an influence on road traffic performance. This relates to the large dimensions of vehicles that require large space and vehicle weight affecting its speed. In a design and evaluation of road networks information regarding the Level of Service (LOS) of roads is required. It is necessary to perform road traffic performance analysis to determine LOS of roads in Surakarta City.

\subsubsection{Data collection}

Primary data related to traffic volume was taken at the morning and afternoon peak hours at 06.45-07.45 AM and 04.00-05.00 PM, respectively. An extensive traffic enumeration survey at an intersection was conducted to obtain traffic volume, vehicle type composition and distribution of vehicle turn movement. Traffic enumeration is done separately for each arm and the direction of traffic. The road inventory survey was conducted to obtain geometric data and road side constraint parameters. 


\subsubsection{Analysis and results}

Road traffic performance analysis was carried out using the method of Indonesia Highway Capacity Manual [6]. Survey data was processed and used to calculate road capacity and traffic speed. Road capacity is determined by several factors including basic capacity and road side constraints. The degree of saturation and traffic speed is a parameter of road traffic performance. The degree of saturation is represented by the value of the volume/capacity ratio. Both parameters are used as indicators in determining the LOS of roads. LOS of the road network in Surakarta City during morning and afternoon peak hours can be seen in Figure 7.
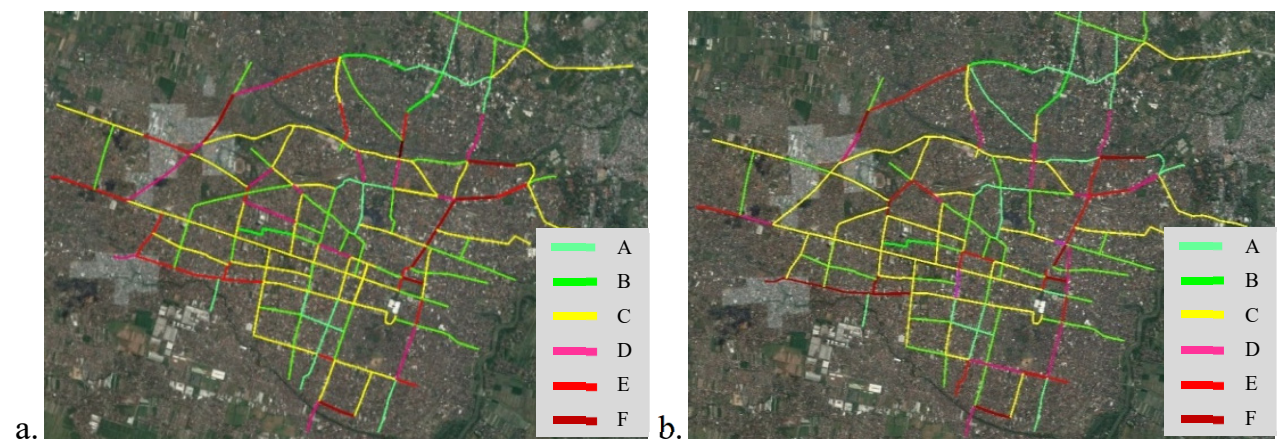

Fig. 7. Map of LOS of road network in Surakarta City during a) morning and b) afternoon peak hour.

\subsection{Traffic violations}

The results of field surveys show that violations of urban freight transport regulations are relatively frequent in Surakarta City. The violations occurred in relation to several matters including violation of the loading procedure [2-5], licensed provisions through the inner city road $[2,4]$, un-proper parking area and loading-unloading activities $[2,4]$, see Figure 1.

\section{Discussions}

\subsection{Characteristics of urban freight transport movement}

Analysis results show that the percentage decrease in the number of licensed urban freight transport between November 2016 and January 2017 was 71.7\%. According to the urban freight transport dispensation license data during January-December 2017 the average number of licensed applicants are 856 vehicles/month [7]. The average decline in the number of applicants in 2017 compared to November 2016 was $73.6 \%$. This phenomenon indicates that the non-functioning of 8 LCPs made the number of dispensation license applicants reduce significantly, so that the violation of urban freight transport entering the inner-city road increased. According to data of sudden operation carried out by DoT and the Police in several locations it is indicated that the number of urban freight transport violation incidents during 2017 has an average of 26 incidents/hour/location [8].

Relatively a lot of urban freight vehicles with weight of $>9,000 \mathrm{~kg}$ enter the Legi Market area and perform loading-unloading activity on the road side between 06.00 AM-06.00 PM. All vehicles with weight $>9,000 \mathrm{~kg}$ do not have a dispensation license issued by the DoT because the DoT only issues dispensation licenses for urban freight transport with weight between $>4,500 \mathrm{~kg}-9,000 \mathrm{~kg}$. These vehicles have a large effect on road damage, safety and 
smoothness of traffic. Therefore, the granting of a dispensation license for vehicles with weight $>9000 \mathrm{~kg}$ needs to be enforced in regulation.

\subsection{Road bearing capacity}

Most of inner-city roads have road bearing capacity of $<7,500 \mathrm{~kg}$. Therefore, some of the existing roads' bearing capacity needs to be upgraded in order to support the distribution of urban goods. Based on the characteristics of urban freight transport movement analysis, roads with enhanced road bearing capacity of $>9,000 \mathrm{~kg}$ includes Sutan Syahrir road, D.I Panjaitan road, Lumban Tobing road, Kusumoyudan road, Monginsidi road; road bearing capacity < 9,000 kg includes Honggowongso road, Gajah Mada road, Gatot Subroto road. Figure 8 shows the map of the upgraded road bearing capacity in Surakarta City.

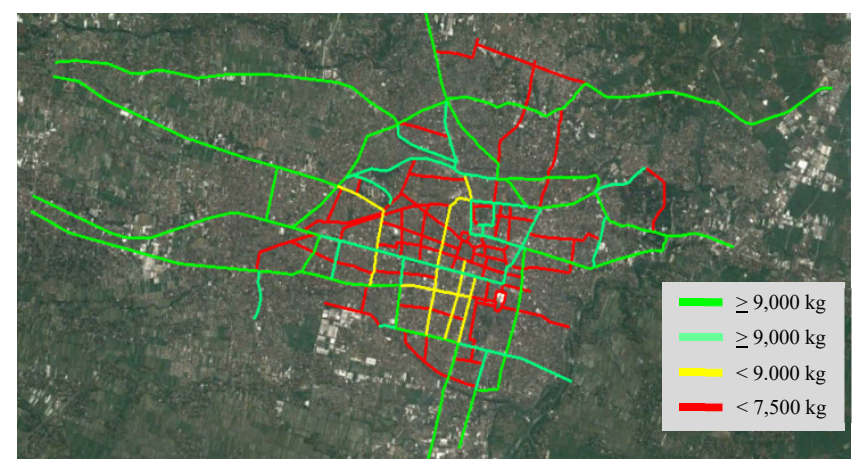

Fig. 8. Map of upgraded road bearing capacity in Surakarta City.

\subsection{Road traffic performance}

The result of road traffic performance analysis shows that in general, the road segment that is used as an urban freight transport route, which has no restriction on vehicle weight, has low LOS (D, E, F). Mostly, inner-city road has LOS C. The results of field surveys indicate that the number of urban freight transport passing through the inner-city road is relatively small, due to the prohibition of urban freight transport with weight $>4,500 \mathrm{~kg}$. If no such restrictions were present, then most likely the inner-city road will have low LOS. In order to avoid traffic problems due to the existence of urban freight transport, therefore, the prohibition of urban freight transport entering the inner-city road, arrangement of parking and loading-unloading hours of urban freight transport for certain weights are regulated by traffic signs.

\subsection{Urban freight transport routes through the inner city road}

The current urban freight transport dispensation license administration system only specifies the origin and destination of urban freight transport. This results in the number of violations of urban freight transport passing through the inner-city road with road bearing capacity that is incompatible with the class road becoming larger. In order to avoid this phenomenon, therefore, the urban freight transport route needs to be determined by regulation. The determination of urban freight transport route is based on the distribution pattern of urban freight transport movement (see Figure 5), road traffic performance (see Figure 7), road bearing capacity (see Figure 8), parking and loading-unloading prohibition of urban freight transport and road class criteria. Figure 9 shows an example of an alternative route of urban freight transport from Jajar to Gede Market. 


\subsection{Urban freight transport dispensation license administration system}

The performance of the current urban freight transport dispensation license administration system needs to be improved in order to increase the level of safety, road service and environmental sustainability. Improvements made such as the dispensation license requirement includes evidence of passing vehicle test, types of goods, urban freight transport routes and operating times; vehicles with weight $>4,500 \mathrm{~kg}$ must be licensed; dispensation license registration through an online system; law enforcement against violations of the provisions of urban freight transport dispensation license with the android system $[8,9]$.

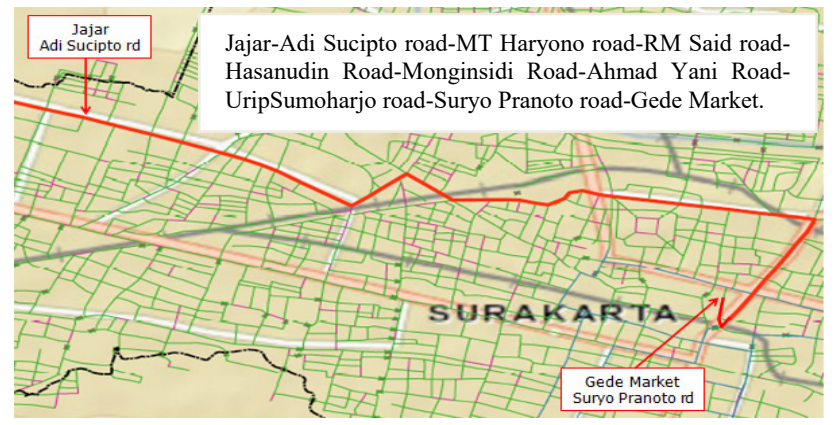

Fig. 9. Route of urban freight transport from Jajar to Market Gede.

\section{Conclusion}

The results of field data analysis indicate that the system of monitoring and controlling urban freight transport has some deficiencies. The non-functioning of 8 LCPs affects the reduction of the number of dispensation license applicants. This potentially increases the violation of urban freight transport. Several efforts to improve the system are carried out by improving dispensation license requirements, vehicles with weight $>4,500$ must be licensed, dispensation license registration through an online system; law enforcement against violations of the provisions of urban freight transport dispensation license with the android system. All these efforts need to be regulated in the form of mayoral regulation to be legally enforceable.

\section{References}

1. The Ministry of the State Secretariat, Government Regulation Number 43 of 1993 on Road Infrastructure and Traffic, (1993).

2. The Ministry of Law and Human Rights, Law Number 22 of 2009 on Road Traffic and Transportation, (2009)

3. The Ministry of Law and Human Rights, Government Regulation Number 55 of 2012 on Vehicles, (2012)

4. Government of Surakarta City, Surakarta City Regional Regulation Number 1 of 2013 on the Implementation of Transportation, (2013)

5. The Ministry of Law and Human Rights, Government Regulation Number 74 Year 2014 on Road Transportation, (2014)

6. Directorate General Bina Marga Indonesia Indonesian, Highway Capacity Manual, (1997) 
7. Department of Transport Surakarta City, Urban freight transport dispensation license data, 2017

8. B. Yulianto, Setiono, Implementation of Android-Based Urban Freight Transport Violations Reporting Application in Surakarta City, AIP Conference Proceedings 1977, 030028 (2018); doi: 10.1063/1.5042948

9. B. Yulianto, Setiono, Android-based E-Traffic law enforcement system in Surakarta City, AIP Conference Proceedings 1941, 020056 (2018); doi: 10.1063/1.5028114 